\title{
Comunidades y antiguo régimen en una región del Perú rural
}

\begin{abstract}
RESUMEN
El testimonio de conflictos entre campesinos, hacendados y redes de poder, rescatados de archivos locales, ofrece la oportunidad de constatar la importancia de los indicadores socio-étnicos que se revelan como significantes en la dinámica social del Perú rural durante la primera mitad del siglo xx.
\end{abstract}

Palabras Clave: Angaraes; campesinos; hacendado; etnicidad; conflicto.

\section{Communities and old regime in a traditional area of Peru}

\begin{abstract}
Conflict between huancavelican peasants, the landlords and power networks; rescued from local archives, offer the opportunity to verify that the socio-ethnics indicators were important and are offered as a gap through which we observe. However, the Andean peasants never lowered their heads where important that are revealed as significant in the social dynamics of rural Perú.
\end{abstract}

KeYwords: Angaraes; peasants; landlords; ethnicity; struggle. 


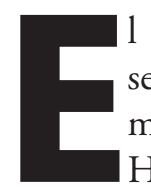
presente artículo presenta muy al ras, una serie de conflictos suscitados entre las comunidades campesinas de la región de Huancavelica y los hacendados locales, mucho antes de la promulgación de la reforma agraria de 1969. En realidad los datos presentados están restringidos al período de 1920-1959.

Algunas razones explican esta línea de tiempo. En primer lugar es muy posible que en este largo período para los Andes, significara una etapa de gran inestabilidad tanto para las haciendas como para las comunidades campesinas, por el cual entraron en escenarios de competencia y conflicto.

A pesar de la afirmación de que la «Patria Nueva» del presidente Leguía descolonizó la llamada «República Aristocrática», también es cierto que en la sierra andina, los mandatos legales de la conscripción vial, acicatearon la ambición de pequeños y grandes propietarios, pero a su vez —en forma dialécticala predica indigenista del mismo presidente, otorgó insumos para los movimientos reivindicativos que se suscitaron.

Si bien está relativamente documentado lo acontecido en los Andes del sur (movimientos vinculados a una supuesta "utopía andina»), es muy poco lo conocido para el departamento de Huancavelica, ese gran ausente que orilla entre la significativa producción histórica y sociológica realizada para el valle del Mantaro y la región de Ayacucho.

Otra razón para esta línea de tiempo, es que hemos recurrido a repositorios documentales regionales y locales. El Archivo Regional de Ayacucho y los papeles sueltos de un archivo prefectural que lamentablemente después se perdieron en Angaraes, fueron la fuente de los datos que ofrecemos. También es necesario advertir al lector que se reproducen algunas notas que ya fueran publicadas (Plasencia 1996) y también partes de la tesis doctoral inédita del autor (2016).

Se muestran pues, algunos acontecimientos que descritos, pueden ayudar a reconstruir el perfil histórico de una región que sigue ostentando los índices más notables de pobreza y subdesarrollo.

Antes, se hará una breve revisión de los trabajos que a nuestro juicio son importantes por cuanto reportan una historia de las comunidades en regiones específicas. Esto es relevante pues desde el siglo XIX, justamente con el avance gradual del capitalis- mo mercantil, es que las comunidades del país sólo pueden ser entendidas a partir de su diferenciación regional. Y esta es inteligible por el carácter y la naturaleza del desarrollo del mercado y su lucha hay veces violenta (como lo predijera Rosa Luxemburgo) con las formas no capitalistas de producción.

Quizás por ello es que los pueblos campesinos de Chumbivilcas, Chucuito, Huanta, Cajabamba o el valle del Mantaro, ostenten significativas diferencias no sólo geográficas, sino sobre todo, económicas, demográficas y socio-culturales; pasando incluso por las idiomáticas.

Aquí queremos mencionar brevemente la interesante comparación entre las comunidades del Tulumayo en Junín con las del Cusco, que hiciera Daniel Cotlear (1989) que ante su semejanza ecológica (incluida la fertilidad de la tierra), la diferencia resultó abismal en cuanto niveles de productividad, recurrencia al mercado y uso de tecnología. Es decir, la circulación de bienes, dinero y fuerza de trabajo y su consecuente desarrollo regional se imponían en la diferenciación inter-comunal.

También el trabajo mencionado de Cotlear (como otros), ilustraba la conveniencia de los estudios comparativos y la cancelación ya definitiva, de los estudios de comunidad, monográficos y excesivamente descriptivos que había impuesto el culturalismo en la antropología peruana.

\section{El campo estudiado}

Jaime Urrutia (1986) en un trabajo presentado al II Seminario Permanente de Investigaciones Agrarias (SEPIA) realizado en Ayacucho, muestra justamente una evolución de las comunidades de la región de Huamanga, en una línea de tiempo comprendida entre 1824 y 1968. Es decir casi todo el período republicano.

Estudio, por lo demás, hecho en archivos departamentales y con la colaboración de alumnos de la universidad local.

Lo primero que resalta entre sus líneas, es la periodificación. Esta preocupación no sólo es un requerimiento de la sistemática, sino también del hecho de que estos períodos compulsados con la política nacional y las fuerzas sociales en juego (la independencia política, el poder de la iglesia, la recupera- 


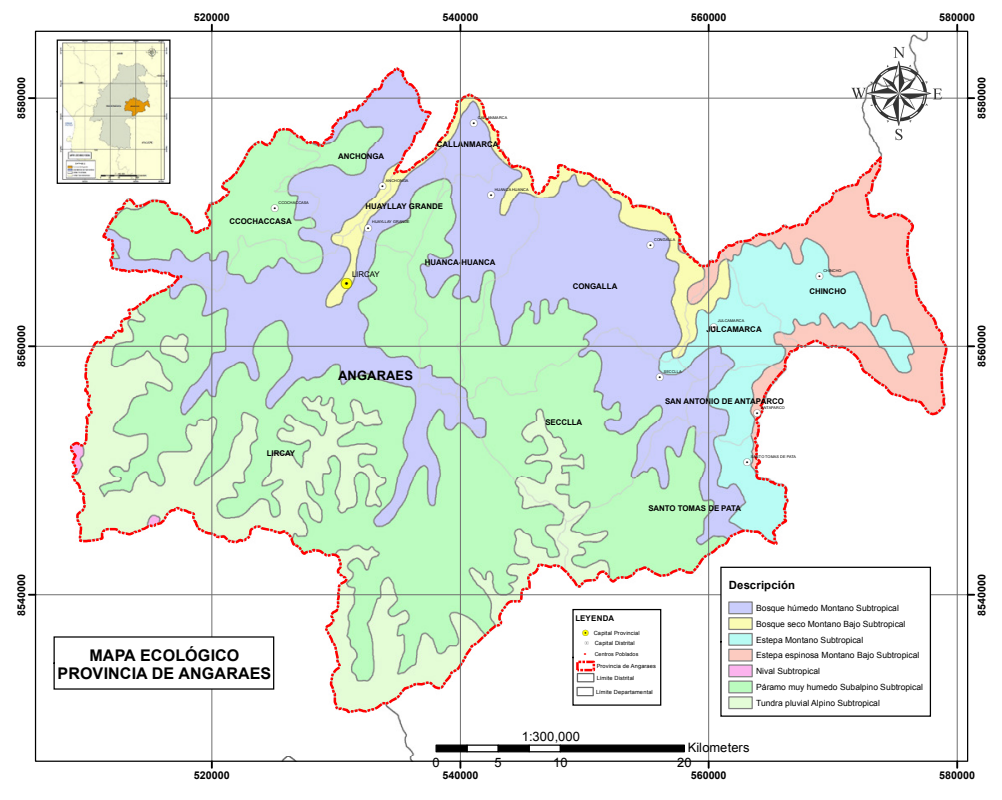

ción demográfica, la guerra con Chile, el leguiismo, la modernización periférica y la reforma agraria de Velasco), van otorgando límites para la actuación y respuesta de las comunidades frente a esa institución que se tornaría en una de las más importantes del Perú republicano: la hacienda. La preocupación por la clasificación temporal además, coincide con lo expresado por Glave (1992: p. 17) de "periodizar las evoluciones regionales».

El período que va de 1840 a 1970, es el de reordenamiento de la tierra y de los fueros comunales. Para esta época ya se configuran espacios sub-regionales que van a determinar en el futuro la economía rural e incluso, el curso de la guerra interna del último tercio del siglo xx.

En la parte norte del departamento de Ayacucho, estará caracterizado por el predominio de las haciendas, por el que "navegan" las comunidades. En el sur en cambio, como en la antigua provincia de Parinacochas; la comunidad tendrá no sólo por su número sino también por el control de los recursos productivos, una presencia determinante y difícil de negar. Permitiendo en ese sentido, una relación de competencia pero también de negociación, con las haciendas del sur ayacuchano.

No es necesario hacer un esfuerzo para plantear entonces, la distinta naturaleza del comportamiento campesino frente a Sendero en el norte y el sur del departamento.
Entre 1915 y 1940 , es el período de la «modernización» de la sierra peruana frente a los intentos frustrados del leguiismo, el Estado empieza con su tímida intromisión. Pero también es el de la eclosión de las ideas indigenistas, o mejor «regionalistas» en Ayacucho. 1940-1968 es en general, el de la bancarrota del poder terrateniente y que el autor menciona como «la movilización campesina por la tierra y la ampliación de los recursos comunales» (p. 462).

Finalmente, son dos las proposiciones que rescatamos de la parte inicial de su estudio exploratorio. En primer lugar, la suposición casi generalizada y anclada ya en la mitología histórica, de la omnipotencia criolla frente a la propiedad indígena en el siglo XIX.

Las comunidades ya desde el siglo XVII, empezaron a mostrar eficacia al momento de defender sus fueros y sus prerrogativas (Stern 1986), empleando justamente las propias herramientas dadas por el estado espańol en Indias y luego por la naciente república.

La afirmación del poder absoluto de hacendados y criollos debe ser relativizada y comparada con las imágenes de la sociedad feudal, ya advertida por Le Goff en su prólogo a un texto medievalista (2009). La edad media (y el antiguo régimen) fueron vistas como sociedades ineficientes tanto por economistas clásicos como Smith, quienes censuraban el estamentalismo que asfixiaba la libertad de comercio, como por los filósofos ilustrados, quienes la vieron como el reino de la oscuridad y la superstición.

Sea como fuere, la edad media sirvió bien para idealizar la modernidad o para denigrarla (como Novalis), exaltando el esplendor y la espiritualidad del medioevo.

La segunda proposición es que los espacios regionales no son homogéneos, es decir que son susceptibles de ser distinguidos internamente en microrregiones para su caracterización.

Comentario aparte merece la atención a los períodos "punta» en el cual las comunidades campesinas gozaron de reconocimiento. En el siglo $\mathrm{xx}$, son los gobiernos de Leguía, Prado y Belaunde en que acorde con sus políticas nacionales de desarrollo, se consideró útil darles reconocimiento legal.

Otro texto que consideramos útil para esta sección es el de Glave (1992) sobre las comunidades de Canas, en el departamento del Cusco. El autor se embarca en una historia de "larga duración» de las 
comunidades indígenas que se remontan del siglo XVI hasta el xx.

Los antiguos canas, tributarios del Estado inca, fueron reducidos por los españoles, siguiendo el derrotero común de colonización en los Andes, y acorde con la política toledana. Pero una vez más, las condiciones regionales y étnicas condicionaron en parte esas políticas.

El re-ordenamiento espacial y la prioridad de las actividades mineras (indesligables del tributo y la mita) hicieron que las viejas y nuevas «regiones» tuvieran caminos paralelos y otros, bifurcados.

Aquí, la comunidad es vista como una "corporación cerrada, basada en jerarquías políticas rotativas y trabajo colectivo y estacional» (p. 13). En ese sentido, las comunidades de Canas (entre las que se encuentran pueblos importantes para la historia colonial como Sicuani o Tinta) activabaron una «tensión segmentada» es decir, de pugna y reciprocidad entre sus «moietes» (los ayllus de la comunidad).

Esta dinámica requiere de un breve comentario. Fueron los etnólogos franceses quienes utilizando las teorías de Levi-Strauss, dieron vida a lo que se ha denominado el «estructuralismo andino».

Es decir el reconocimiento de "principios de orden» que a pesar de las contingencias históricas, se han mantenido hasta el presente. Así mismo, el uso del concepto de "sociedades segmentarias» que la antropología británica tomó de las sociedades africanas, fue utilizado para entender lógicas de faccionalismo y de conjunción escalonada en los distintos segmentos sociales que conformaban los ayllus (Izko, 1991; Ossio, 1996).

Por otro lado, la importancia del trabajo de Glave estriba en que la historia de la sociedad cana, se torna importante en el período de 1780 , que como sabemos fue un período de tensión y violencia social que marcará el derrotero sufrido por los campesinos en sus procesos de diferenciación social y su articulación a la "sociedad nacional» de siglo xIx.

Plantea para este siglo un repunte demográfico, quizás como consecuencia de la «reconstitución étnica» ocurrida en el siglo XVIII en la región. La integración de los foráneos a las comunidades de la región, permitirá además, estrategias de colonización en espacios abiertos como las punas, para practicar actividades económicas itinerantes (p. 67).
Esta proposición nos obliga nuevamente, a una comparación con lo sucedido en Castilla en el siglo XII, cuando el re-poblamiento de la zona extremeña fue realizado por campesinos y «nobles villanos» que instauraron propiedades municipales y comunales; como lo sucedido en Cuenca o Plasencia. A diferencia de las Órdenes Militares, jerárquicas y con sistemas complejos de vasallaje (Valdeon, 1980).

Finalmente del texto no dejamos escapar la religiosidad campesina. Hoy considerada como el reducto de las identidades locales (e incluso étnicas), en realidad tuvo fuertes ingredientes económicos y de control político (aquí es necesario reconocer los trabajos pioneros de Antonio Acosta).

En Condorama por ejemplo, los curas llegaron a «establecer un candelario de 16 fiestas anuales» (p. 125), que significaba el pago de limosnas. En la localidad de Yauri a fines del siglo XVIII, se registraban unas 24 cofradías con sus respectivas limosnas, que ascendía incluso a 170 pesos anuales por cada una. ${ }^{1}$ La fiesta fue entonces una oportunidad sociológica para legitimarse ante el universo sagrado y el poder político. No sólo era una muestra del pacto colonial entre Estado y las reducciones indígenas, sino que también permitió desarrollar en el seno de los ayllus, sistemas de diferenciación social, incentivando el despliegue del prestigio en actores que empezaban haciendo carreras políticas a nivel local.

El gasto en la fiesta, también terminó por articular plenamente a la población indígena con el importante mercado del sur del virreinato, dinamizado por la minería.

Finalmente, tenemos un libro importante sobre los chipaya de la actual Bolivia. Nos referimos a $E l$ regreso de los antepasados. Los indios urus de Bolivia, del siglo XX al XVI de Nathan Wachtel (2001).

La investigación del autor, nos remite a dos aportes que consideramos fundamentales. El primero es de índole metodológica y la otra, etnográfica, en la mejor tradición francesa: el estudiar en detalle una comunidad amerindia y a partir de ahí, explorar la identidad étnica que como étnica, esconde en su seno haces de identidades sociales, locales, memoriales y lingüísticas.

1 Las cuatro parroquias de Huancavelica por ejemplo, llegaban a rendir entre 4 mil y 7 mil pesos, donde precisamente se fomentaba la devoción de los indios «para lograr mayor contribuciones de los feligreses» (Molina 1995: 139). 
Wachtel nos muestra una "historia regresiva», método que propugnó Bloch y que al decir de Gardet en un artículo sobre Francois Chevalier (2008), era una forma de remontar el tiempo desplazándose por el espacio. Es decir partir de la etnografía hacia la historia, del presente hacia el pasado y de lo conocido a lo menos conocido.

«Larga duración» como el estado teórico más importante de la historiografía francesa del siglo xx. No en vano, Lucien Febvre aleccionaba sobre la necesidad de preferir el cuadro regional por el de la cronología.

En ella, la etnología ofreció un soporte vigoroso cuando se exploraron temas como las mentalidades, la vida cotidiana o la brujería en la edad media. También significó la extrapolación de categorías surgidas en los extramuros de la humanidad colonizada para la propia sociedad europea. Mauss, Levi-Strauss, Griaule, Bastide entre otros, fueron las nuevas herramientas para los historiadores (que para Peter Burker es cuando la historia coloniza a la antropología).

Wachtel representa pues, esta tendencia al estudiar los chipaya, un grupo social que hablaba el puquina (una de las tres lenguas generales del virreyanto), que habitaban la parte sur y árida del altiplano boliviano y despreciados por los aymaras (los otros de los otros). Parte de la idea del dualismo y la cuartipartición (conjuntos simétricos) como principios ordenadores de las relaciones del hombre chipaya con sus semejantes, con su territorio y su cosmología.

En el capítulo titulado "Juego de espejos», trata sobre el tema. Las comunidades activan en su frente interno a sus parcialidades o ayllus, para establecer un péndulo constante entre ch'axwa (el conflicto) y tinku (el encuentro), ambas necesitan de la jerarquía y la reciprocidad, como la única manera de aproximar las partes o los sub-conjuntos.

Pero esto va más allá: según Platt (1987) al diseñar su modelo de "Estado segmentario», la sociedad andina a través de estos conflictos además de «impedir la consolidación de un poder centralizado (válido sobre todo para el pasado), siguen constituyendo de manera precisa referentes de la identidad étnica» (Izko, p. 99).

Es decir, los conflictos ritualizados impedían la constitución de un Estado andino fuertemente centralizado y puesto a merced de la negociación inter-étnica. De este modo, se apela a una conocida hipótesis de la etnología francesa, apuntalada por los trabajos de Clastres (2001) sobre la guerra primitiva y la posible unidad sociológica o por lo menos de proximidad/relación entre las sociedades campesinas y las bandas recolectoras de Sudamérica, anunciadas inicialmente por Vellard y Metráux y continuada por Saignes (1985) y Renard-Casevitz (1988).

Estos principios de duplicación (los espejos) están repartidos en varios planos. En lo societal, los ayllus Tuanta (Este en Puquina) y Tajata (Oeste), y en lengua aymara Manasaya (la parte de Abajo) y Aransaya (Arriba), permiten la agrupación de grupos de viviendas relacionadas con ciertos linajes o patronímicos (dos y tres en cada mitad), delimitando las fronteras con los otros próximos o lejanos.

Esta distribución a su vez, permite la clasificación del espacio en diferentes oposiciones ecológicas y productivas: ganadería/agricultura, húmedo/seco, puna/ pampa, salvaje/doméstico; pero también codifica la relación con lo sagrado (manantial de toda eficacia), separando lo sagrado de lo profano, inscritos en el espacio y el tiempo (el calendario festivo), entre santos ocultos y constanticios, entre lo católico y lo sincrético.

Todos estos niveles son activados por los cargos cívicos y religiosos en una estructura jerárquica que descansa a su vez, en distintos niveles de reciprocidad que van del linaje, al ayllu y a toda lo comunidad.

Obviamente Wachtel es consciente que estas estructuras han sufrido profundas modificaciones, que fueron aceleradas en el siglo xx. La reforma agraria boliviana de 1953 que generalizó el minifundio en el altiplano, la penetración de las instituciones estatales y de mercado, así como la importancia del pentecostalismo, hicieron que muchos de estos arreglos sociales e ideológicos vayan perdiendo intensidad e importancia. Riviere (1983) lo confirma en Carangas (Oruro) y Abercrombie (2006) en K'ulta en la misma región.

De ahí que de la memoria campesina de esos cambios y de sus continuidades, se quiera extraer principios de identidad étnica/local preocupación con la que finaliza su voluminoso estudio.

Sin embargo, hay otra conclusión deducida del método regresivo. Es el hecho de que en el siglo xx, el estudio parte de comunidades atomizadas muchas veces enfrascadas en luchas por la distritalización, convertidas ahora en una forma de visibilización ante el Estado nacional. Pero conforme se va retrocedien- 
do en el tiempo, el autor encuentra que la sociedad indígena está incorporada a conjuntos sociales más amplios, que llegando al siglo XVI, nos encontramos con verdaderas sociedades macro-étnicas, en un recorrido semejante al de un cono invertido.

\section{Las comunidades de Angaraes}

Es con el vendaval de la conquista que el territorio Angara es re-constituido y adscrito al Obispado de Huamanga. Favre en su estudio pionero sobre las haciendas huancavelicanas (1976) menciona dos visitas, la de 1620 y 1713, como las encargadas de arreglar y «componer» los territorios indígenas.

El corregimiento de Angaraes será en ese sentido, el principal proveedor de mano de obra para las minas de Huancavelica y también una importante fuente de tributación. Junto con Cotabambas (Apurímac) y Chumbivilcas (Cusco), otorgaban indios de mita. Los de Angaraes aparte de mitar hacían trabajos especiales, como los llamados Rosas y que se dedicaban a labores de acarreo y limpieza de las minas durante un mes, mientras los indios de Huancavelica (parroquias) lo hacían durante una semana, cobrando 4 reales diarios (Molina, 1995).

$\mathrm{El}$ «Anónimo de Angaraes» (Jiménez de la Espada 1965) como «La memoria y descripción...» del obispo Verdugo (producto de su visita pastoral a la diócesis de Huamanga entre 1624 y 1625), mencionan en sus revistas, las comunidades originarias que surgieron de la reducción de viejas aldeas pre-hispánicas y que serán el origen del caleidoscopio comunal que hoy caracteriza al territorio huancavelicano. Moya, Vilca, Cuenca, Conaica, Hatun Huayllay, Callanmarca, Añancusi, Pallalla o Lacroja, son nombres que desfilan hoy en los archivos.

Muchas de ellas fueron constituidas con ayllus o barrios que albergaban a los mitmas que introdujeron los cusqueños: quiguares, chancas, caxamarcas y huancas entre otros, que aparecen "salpicados» en las reducciones, revelando la "disturbación étnica» emprendida por los incas.

Angaraes en un inicio, fue repartida en tres encomiendas: la de Amador de Cabrera el descubridor del cerro de Santa Bárbara, el de Baltazar de Hontiveros y el de Hernán García Gallardo (que luego heredaría su hija, Elvira García), en esta última estaba el corregimiento de Huayllay Grande, que era además un curato importante de la doctrina de Lircay. Toda Angaraes, poseía en total, 3,559 indios tributarios.

Según el «Anónimo» en la provincia existían hacia 1586, 8 puentes de cal y canto, y 7 de crisnejas sobre el Angoyaco (uno de los nombres del río Mantaro), lo que revela su importancia como conexión y tránsito hacia Huamanga y el Cusco.

En los tiempos de la visita del obispo Verdugo (1626) existían 4 doctrinas en el corregimiento de Angaraes. En la doctrina de "Guayllay» existían 4 pueblos: Guayllay, Ucchuy Guayllay, Lircay, Callanmarca y Guanca Guanca.

Dos encomenderos controlaban a estos pueblos y sus respectivos anexos, a través de dos mitades: una entregada a Antonio Pérez de Aguilera y la otra a Miguel de Bendezú. El pueblo de Guayllay poseía 270 almas y en ella, se registraba un "yngenio de oro» propiedad de Pérez de Aguilera y «dos estancias» de Thomas de Contreras. En 1790 el corregimiento de Angaraes poseía 3,290 tributatios con tierras, una de las tasas más altas de la región (Povea, 2014: p. 51).

No hay registros de Guayllay como un obraje, pero es cierto que tuvo cierta fama por su actividad textil. Lo reporta Raimondi (1942), cuando pasa por el lugar rumbo a las minas de Vizcachas que existían ya, desde tiempos pre-hispánicos. Igualmente en muchas ferias de la región, en un radio que alcanzaba hasta Andahuaylas (posiblemente el área de influencia de la peregrinación del cristo de Huayllay), se registra el ingreso de paños provenientes de este importante pueblo.

La actual provincia de Angaraes, junto a las de Acobamba y Huancavelica, conforman pues, la «zona nuclear» del departamento; expresión acuñada por el propio Favre. Y esto es así por la sencilla razón de que las actuales provincias de Tayacaja (la antigua "península de Tayacaxa»), Churcampa y Castrovirreyna /Huaytará, están conectadas con espacios regionales extra-departamentales como son el valle del Mantaro, Huanta y los valles irrigados de Ica, respectivamente.

En Angaraes pueden, en atención a nuestro planteamiento, ser identificados espacios menores o micro-regionales en mérito de la cuenca que habitan, a su conexión con los centros político-administrativos, su producción agrícola, su organización social e incluso el destino de su población migrante. 
a) Espacio 1 (poca continuidad espacial). En primer lugar tenemos las comunidades que gravitan alrededor de los distritos de Congalla, Seclla, Chincho, Santo Tomás de Pata, Antaparco y Julcamarca. Su declive es menor, por el cual la producción de maíz es importante. Los ríos Chuyacc y Cachi, enmarcan sus límites en dirección este hacia la cuenca del Mantaro, a través del Urubamba y el Pangora.

Su conexión con la ciudad de Ayacucho es vital, pues de esa ciudad provienen las remesas y los bienes mercantiles, y a ella se dirigen los comuneros en una dinámica pendular.

b) Espacio 2 (continuidad espacial). Aquellas alineadas a lo largo del río Lircay atravesado por el Chontacancha; en dirección hacia la provincia de Acobamba. Son las viejas comunidades matriciales: Huayllay, Callanmarca, Huanca Huanca y Anchonga. Poseen dos zonas claramente diferenciadas - $\mathrm{y}$ articuladas-, la zona quechua y de puna. El universo ritual vinculado tanto al ámbito familiar como al de autoridades comunales es aún importante. Sus iglesias barrocas construidas en el siglo XVII, atestiguan su antigua importancia.

c) Espacio 3 (niveles altos de articulación en torno a un centro). Son las comunidades de la cuenca del río Sicra y Ajohuarma, afluentes del Lircay, que están alrededor de la capital de la provincia. Tienen una importante vocación ganadera y se constituyeron en comunidades como consecuencia de la afectación de haciendas y fundos cercanos a Lircay, durante el proceso de reforma agraria, como fueron Pampas, Constancia, Chahuarma, Yanaututo, Buenavista u Ocopa.

\subsection{Comunidades: quejas y rencillas}

En 1732 se levantan los campesinos indígenas por abusos cometidos por el español Eusebio Joaquín de Azores en compañía de un jesuita llamado Rafael Hernández. Un alcalde indio de Castrovirreyna los detuvo y los condenó a muerte, siendo ejecutados ante la comunidad. Aunque no estaban facultados de detener y juzgar a los espańoles, el virrey Castelfuerte aprobó su conducta.

En 1765 la población de Moya (al norte de Huancavelica) se levanta descontenta contra las autoridades coloniales y es sofocada violentamente. En 1821, en plena lucha por la independencia, el jefe de las milicias guerrilleras José Félix Aldao vuelve desde Tarma (en la sierra central) para recuperarse de la derrota de Huancayo y reactivar las montoneras huancavelicanas. Con ese propósito se dirige al puente de Izcuchaca para contener al general Carratalá.

El puente de Izcuchaca sobre el río Mantaro es un paso obligatorio que une el valle del Mantaro con el sur del país. Construida en 1560, fue reconstruida en 1847 por el prefecto Juan Salaverry; fue escenario estratégico en la guerra de la independencia, en las guerras civiles y en la resistencia contra los chilenos (Plasencia, 2016: p. 248).

Las arqueólogas Lavallée y Julien (1983) han confirmado que el puente de Angaoyaco (su antiguo nombre) era cuidado y vigilado por mitmas orejones, pues en sus excavaciones encontraron vasijas y artefactos cusqueños. 800 metros más arriba están las viejas comunidades de Cuenca y Conaica.

El 17 de mayo de 1824 los indios de Moya sorprenden una avanzadilla de 20 hombres y «con hondas y piedras que arrojaban de los cerros» mataron a cinco jinetes españoles.

Sobre este aspecto, ha sido largo el debate sobre el carácter de la participación indígena en la revolución de la independencia. Fue Heraclio Bonila (1981) quien expuso la tesis de que nuestra independencia había sido concedida por las corrientes liberadoras del sur (San Martín) y del norte (Bolívar), pues las élites peruanas no solo eran reacias a su libertad política, sino que enraizadas en Lima - el centro del virreinato- habían sido enervadas en su afán revolucionario por su actitud cortesana y dependiente. Esta tesis compartida con Karen Spalding casi le cuesta la deportación al autor, pues cuando se publica el libro, el país celebraba el sesquicentenario de su independencia con una Comisión Histórica creada por el gobierno militar.

La tesis de Bonilla en cierto modo recogía la de Mariátegui [1928], sobre el carácter epidérmico e inconcluso de nuestra independencia, a diferencia de las burguesías de Caracas o del Río de la Plata. A pesar de algunos aportes previos sobre la participación popular e indígena en la gesta emancipadora (Vergara 1974), ha sido O'Phelan (2001) la que ha matizado esta divergencia, explicando que si bien la postura de las clases criollas fue cauta y tibia, hubo a la vez una destacada participación indígena y popular en la lucha por la emancipación. 
La tesis generalizada es que la población indígena de los Andes, fue refractaria -pero no indiferente- a la guerra de la independencia. Primero porque esta fue hecha por criollos muchos de ellos propietarios, con objetivos políticos como los de libertad, independencia y liberalismo, muy lejanos de la preocupación indígena.

Segundo, muchas comunidades - como las de las alturas de Ayacucho o los pastuzos de la Gran Colombia- les convenía el llamado "pacto colonial» entre los indígenas y el Estado español en Indias, en la que a través del tributo se garantizaba en cierta forma, la inalienabilidad de las tierras colectivas.

A fines del siglo XIX se suscitan algunos conflictos. En 1896, Lorenzo Yauri, vecino de Huayllay Grande, protesta ante el Subprefecto: el Alcalde Municipal no hace caso de sus reclamos sobre los excesos en el cobro hecho por el «rescatista» Apolinario Monge, sobre unos pastos de Huanca Huanca, además dice el vecino, «me ha arrebatado tres llamas». Ello lo atribuye no sólo al mal carácter del mencionado rescatistas, sino al «estado de proletarismo en que se encuentra la raza indígena». Obviamente esta prédica no tenía la misma naturaleza que la iniciada 25 años después, con discursos más orgánicos y políticamente viables.

El mismo año de 1896, al producirse la rebelión de los iquichanos en Huanta por el llamado «impuesto de la sal», huestes de aquella rebelión invadirían Caja a la fecha, jurisdicción de Angaraes; también estaban comprometidos Lacroja y Mayocc, en la antigua Tayacaja.

Resulta evidente que la mentada movilización indígena no se restringió a la provincia huantina, como generalmente se ha sostenido. Las autoridades lirqueñas, alarmadas, sindicarían como cabecillas de la incursión, a Luciano Ccoyllar y Nazario Capcha. Se los acusaría de atacar con quince hombres la hacienda Waterloo, en Marcas, propiedad de Bacilio de la Vega:

[...] me han avisado, de que aquella villa, se encuentra ya casi sin habitantes y las casas vacías, porque están retirándose la mayor parte a la ciudad de Ayacucho, unos al lado de Mayocc, otros a Julcamarca y los demás a los puntos de Marcas y Cuñi de este Distrito, por ser amenazados por los indios que en las alturas están marchando, que- riendo hacer nueva invasión a Huanta y formar degüello en toda clase de personas y saquearlos. ${ }^{2}$

En noviembre de 1877, la comunidad de HuancaHuanca había demandado al Municipio de Lircay por un asunto de «reivindicación de pastos».

En 1914, Domingo Vidalón —una de las familias más poderosas del departamento- tenía encausado a Mariano Sullca "por robo». Un «notable» podía como vemos, denunciar por delitos comunes a los plebeyos y a los indígenas de las comunidades: era una especie de modalidad de la «administración étnica del poder.»

Este mismo personaje en 1887, tenía también otro proceso en contra de José Rosell por «saqueo e incendio». El cura Dámaso Vidalón ejercía cómo "garante» en la demanda del propietario Wieland, quien acusa de robo y «sustracción» en 1915, a los operarios Pedro Pérez y Víctor de la Torre, para no pagarle sus honorarios.

Eduardo Larrauri otro miembro connotado de la sociedad local, acusa en abril de 1923, a Gabrielano y Pablo Hilario Ichpas, junto a Esteban Melchor por «robo de llamas» y "homicidio frustrado».

En marzo de 1928, el apoderado Abraham Delgado de la «Sociedad Minera Vizcachas» — propiedad de Demetrio Olavegoya hacendado de la sierra central- acusa a Félix Oré e Ignacio Calderón por el robo de «especies».

Los cierto es que este propietario minero no encontró mejor forma de escamotear sus sueldos atrasados, que acusándolos de ladrones.

Aunque algunas veces, eran los comuneros indígenas quienes hacían las acusaciones. Alejandro Vidalón y Juan Abrabovich, fueron sindicados por Santos Huincho de Huayllay Grande, de ser responsables de "delitos contra el patrimonio» en su agravio.

En octubre de 1905, Fernando Wieland (emparentado con hacendados), había demandado a Urbano Gutierrez «por despojo municipal». Ya en el siglo xx, en octubre de 1907, el alcalde de Lircay Vidal Landeo, acepta la petición hecha por Leonor Vidalón viuda de Uribe, de que asistan «...un número de individuos de cualquiera comunidad perteneciente a este cercado para ensanchar la acequia (sic) pública de la calle del Comercio que atraviesa por el

2 Oficio del Gobernador de Caja al Subprefecto de Angaraes, 22 de octubre de 1898. Archivo Subprefectural, Lircay. 
interior de una propiedad suya...». El alcalde oficiaría al subprefecto para que inmediatamente se ponga a «disposición de la señora (...) los indicados diez comuneros».

Diez años más tarde, los comuneros de Huayllay Grande, secundados por los de Huanca Haunca, Carhuapata, Achonga, Huayllay Chico, Callamarca y Allato, con "gran tumulto", se quejarían de los excesos del cura, en la plaza de Lircay.

Sería a partir de la siguiente década cuando el campesinado de la región, ante «el impase respecto al desarrollo de la modernidad política condujera (a) adherirse a los movimientos denominados por los investigadores como "utopía andina», tan importantes en la década del 20»(Gamarra, 1992: p. 111).

Sólo así se explica que en agosto de 1923, Miguel A. Parra, Ayacucho y vecino de Congalla, se dirigiese a las autoridades de Lima, y acuse a los delegados de la Asociación Pro-indígena, que han:

definido edeas [sic] odiosas en el ceno [sic] de la comunidad, tendiente a [...] restaurar el régimen del Tahuantinsuyo: [...] han tomado una actitud subersiva y se han declarado en abierta rebelión contra la comunidad.

El plan, según él, era amedrentara los propietarios, «desalojándolos para apoderarse de sus propiedades y convertirlos en tierras comunales».

Al mes siguiente, los comuneros de Pirca, Chahuarma, Huallarpo, Ahuay, Secclla, Congalla y Huanca Huanca, se dirigen al Ministerio de Gobierno y se quejan del subprefecto Santillana «i compañeros» por numerosos abusos cometidos. El espíritu de la época hacía que los conflictos sociales y étnicos no sólo se dirigiesen hacia los hacendados, sino incluso hacia los pequeños propietarios mestizos residentes en las comunidades. No estaba lejana la imagen de la guerra de "castas» que se iniciaba en el sur andino.

Es posible que alrededor de ese ańo, en 1923, se haya producido el intento de una sublevación indígena que trascendiese las protestas meramente locales y que encadenase la revuelta iquichana con el activismo indigenista en la región. Es una afirmación que sólo manejamos, en todo caso, a manera de hipótesis. Un telegrama llegado de Huancavelica el primero de octubre de 1923, nos lleva a pensar de esa manera:
Tengo el conocimiento que dos mestizos ayacuchos disfrazados indios introduciose distrito Acobamba, a fin soliviantar indígenas. Averigue dando cuenta.

Prefecto Remond.

Más aún, en 1925 ciertas autoridades judiciales dan cuenta de que los cabecillas de una «sublevación indígena» estaban en la cárcel de Lircay, y que se caracterizaban por su hostilidad hacia la familia del diputado Vidalón.

José D. Cazorla, ex subprefecto de la provincia, era encausado en 1926, por abusos cometidos contra los comuneros del caserío de Pirca, junto a un alférez de la novísima Guardia Civil; el Juez de Lircay aducía que "no ha llegado el caso para hacer consulta a la Corte Superior...». Igualmente, en enero del mismo año, Luciano Quispe, indígena de la misma localidad, denuncia a los «hijos de Silva Lozano, Jesús Vidalón» y un "tal Mauro Valdeavellano", por ser "abusivos ya conocidos por haber adquirido bienes del extinto don Ambrosio Vidalón». Los acusaba de asaltar y robar ganado a su madre y su hijo, obviamente el Subprefecto Larrauri declara «ser infundada la queja».

En el mes de febrero, los comuneros de Chincho y Chuyayaco, pertenecientes al distrito de Julcamarca, denuncian abusos por parte de la familia Ruiz, «haciéndose servir con sus animales de manera gratuita». Posteriormente, un notable local, José María Gálvez responde, en marzo, con una larga carta a la autoridad política de Lircay, en el que testifica la «honorabilidad» de dicha familia, pues, «no tienen el espíritu de cometer abusos». Dicha carta seria prueba suficiente para no seguir con el caso, En octubre, los alcaldes vara de Huayllay Grande y de Huayllay Chico, denuncian a diecisiete lirqueños «de reconocidas familias» por el robo permanente de llamas y acémilas; también estaban involucrados mestizos de Callamarca y Huanca Huanca. Casi a fines de 1926, el diputado Falconí telegrafía a la subprefectura, y se queja por utilizar la fuerza contra las comunidades, para la construcción de la carretera de Lircay hacia Huancavelica.

Asimismo, encontramos que a fines de agosto de 1959, el juez de paz de Lircay, Mauro Valdeavellano, tío político de una maestra, dispuso el arresto y detención de las autoridades de Huayllay Grande por solicitar su cambio. El primero de enero de 1960, 
el subprefecto Soldevilla García, juntamente con el inspector de educación de la provincia, amonestaría nuevamente a las mencionadas autoridades comunales por solicitar el cambio de «la preceptora Aura Robles de Vidalón». Ignoramos las causas que aducían los varayoqs.

Para concluir con este significativo recuento, tenemos a la vista un oficio de mayo de 1959, en que Teodoro Pizarro natural de Jauja y residente en el barrio de Ballavista de Lircay; se queja ante el prefecto del departamento Alfonso Cárdenas, de que Cesáreo Pellane y su esposa Rita de la Barra viajaban y se hacían trasladar bienes en el autobús del denunciante, sin pagar un centavo. Lo interesante del caso es que cuando el transportista se queja ante las autoridades, estos le insultan: "Jaujino muerto de hambre, so ajo por aquí y so ajo por allá».

No olvidemos que Alfredo Pellane hijo de Cesáreo, era el subprefecto de Lircay, es por ello, que a Pizarro lo detienen en la comisaría local. El oficio pues, nos revela finalmente no sólo el uso personal del poder, sino la impunidad de los notables y su reacción ante situaciones que ya anunciaban una modernidad tardía, sobre todo en manos de pequeños empresarios foráneos (Plasencia 2016).

\subsection{Hacendados en su laberinto}

Hasta bien entrado el siglo $\mathrm{xx}$, la provincia de Angaraes dependía en muchos aspectos de la administración judicial y esclesiástica de Huamanga, la capital del departamento de Ayacucho. En su Archivo Regional existe una valiosa documentación sobre las quejas y alborotos entre campesinos, aventureros y hacendados de la provincia.

Muchos de estos conflictos se refieren a casos de abigeato, conflictos entre hacendados, intentos de «rebelión»y escenas de sus vidas cotidianas (como el estupro o el robo) y que van de fines del siglo xIx hasta la tercera década del xx. Ya en 1920 los expedientes judiciales hablan de la «asonada de Pumaranra».

El 20 de agosto de 1921, se da inicio a un juicio contra Froilán P. Alva por el delito de «asonada». En el mes de octubre, es acusado Gregorio Zanabria por el cobro clandestino de contribuciones que hizo a «las comunidades de indígenas de Chahuarma y Pirca», más adelante ya en 1924, son enjuiciados junto a los mestizos Dámaso Marcelo y Pedro Soto, por «rebelión y asonada».

En 1923 el juez de Lircay, Manuel Villanueva abre instrucción el 12 de junio a Víctor Ronceros y Teodoro Salazar miembros del «Comité Pro-Derecho Indígena» de Congalla, por «rebelión y usurpación de autoridad». Al igual que Víctor Ronceros quien estaba acusado junto a otros personajes por «rebelión en 1925.»

Esta década estaba en cierto modo, encarrilada con una serie de conflictos sociales si bien, embadurnados en la trama legal, despedían un aliento de crisis y de enfrentamiento hacia los hacendados y mineros. Esto se verifica cuando examinamos las querellas entre las comunidades y los "pequeños blancos» (término utilizado por Favre) que quizás alentados por la expansión del mercado regional, envidiaban las tierras colectivas, sujetos a un brusco aumento de su valor.

Por eso en 1928, la comunidad de Chincho (ubicada al este y casi fronteriza con Ayacucho) entabla un juicio contra Tarciso Ruíz por «deslindes» de propiedad. Antes en 1906, la comunidad de Parisa en la vecina provincia de Acobamba había sido demandada por Raymundo de la Vega.

Huayllay Grande también lo había sido por el mestizo Domingo Gutiérrez por «asuntos de propiedad». El hambre por la tierra también alcanza a los hacendados que pugnan entre ellos. En 1896, Paula Merino de Alarco denuncia a Fernando Wieland yerno de Apolinario Zúńiga, por despojarlo — junto a indígenas allegados- de su hacienda Palcas. ${ }^{3}$ El aparato de choque del más poderoso se pone en marcha: acusan al juez «un tal Anchorena» de tener animadversión hacia la familia de Zúñiga.

Al siguiente ańo, nuevamente Wieland se enfrenta con Melchora Cavero viuda de Delgado, por la propiedad de Rumichaca, una hacienda triguera ubicada al sur de la villa de Lircay.

El yerno de Apolinario Zúñiga aducía que la mencionada hacienda le había sido vendida en mil soles, por la hija de Melchora; Lastenia Delgado y

3 Entre los diplomados en 1926 de la antigua Escuela Nacional de Agricultura, figura Guillermo Wieland, hermano o pariente de Fernando. No olvidemos que América Latina asiste en las décadas que van de 1920 a 1930, a un afán modernista, patrocinado por los gobiernos. En ese sentido, las universidades "técnicas» deberían constituir una clase profesional que apuntalase los intentos de modernización agrícola e industrial. 
su esposo sobreviviente Santiago Flórez. Lo curioso que en esa supuesta transacción aparecen «depositarios» (Eulogio Serpa), garantes (José María Gálvez y el cura Dámaso Vidalón) y beneficiarios con acceso (Julio Zumaita y Domingo Vidalón), todos ellos de la clase de los propietarios. ${ }^{4}$

En 1925, Wieland vuelve a las andadas, esta vez acusa a Natividad Alarco viuda de Larrauri por «robo de reses», ignoramos como terminó la causa judicial.

En Acoria en 1809, el gobernador Miguel Gálvez demanda al juez Agripino Rojas «un ambulante sin garantía» por intento de "homicidio frustrado» en contra del Dr. Uldarico Castro párroco de la localidad y Vicente Alarco.

Las faltas sexuales también expresaban esa tensión. Aparentemente las víctimas eran hijas de los propietarios más poderosos de la región. Eran estupros a secas, o a través de las demandas se «restauraba» el honor de las damas criollas y se castigaba al transgresor.

Cirilo Oré es acusado de estupro en agravio de Josefina A. viuda de Vidalón en octubre de 1921. En setiembre de 1932, Jesús Manrique es sindicado en Lircay de haber raptado a María Vidalón, hija de Mariano Vidalón quien hace la denuncia. Dos meses después a Remigio Cangalaya Samaniego, se le acusa de haber «agredido sexualmente» a Patrocinia Z. de Vidalón. Por lo visto el tal Remigio por sus apellidos, era oriundo del valle del Mantaro una región casi sin existencia de haciendas y con una economía regional más robusta. ¿Fue entonces un caso de seducción o agresión?

En 1936 un grupo de comuneros de Piscobamba y Latapuquio cercanos a Lircay son encarcelados por haber intentado apropiarse de las tierras de Huayllay Chico.

\subsection{Abigeos}

De la conocida tesis de Hobsbawn sobre el «bandolerismo social", siempre se ha interpretado el abigeato y el robo en las sociedades rurales como un mecanismo redistributivo, tupido de relaciones de lealtades y alianzas. Su aceptación y apoyo por parte de los campesinos, también pueden situarlos en el escenarios

4 En 1920 El Tribunal Superior de Ayacucho eleva una terna de jueces de paz para Lircay, entre ellos estaba Domingo Vidalón, es decir la consolidación de una estructura de poder misti a escala local. de «formas cotidianas resistencia» (Scott y Sanchis, 1997).

En los Andes se ha planteado de manera similar (Aguirre y Walker, 1990). El abigeato sería una sanción social con el fin de perjudicar entre otros, a quienes concentraban la tierra y el ganado en la sierra peruana.

Es por eso la extrema punibilidad y estigmatización de los transgresores en todos nuestros códigos civiles $^{5}$. La tesis de jurisprudencia del huancavelicano Mario Camacho de 1938 y defendida en la Universidad de San Marcos, es reveladora sobre este aspecto. Su percepción sobre los indios de la región resume siglos de colonialismo aún intactos:

El indígena aislado en su pequeña existencia, vive sin ninguna perspectiva de mejoramiento. $\mathrm{Su}$ mentalidad estacionaria no le permite sino pensar en las funciones primitivas de la nutrición y reproducción y para llenarlos se dedica (...) al robo de carneros o llamas [...] y a la posesión violenta de la hembra, cayendo así en la delincuencia (1938: 3).

A continuación el futuro abogado instruido en el positivismo legal, relata un hecho ocurrido en la época. En Huando al norte de Huancavelica, en una diligencia por demarcación de linderos entre la comunidad y un tal Genaro Ponce, matan a pedradas a este último. En palabras del tesista:

para luego cortarle cabeza y los pies con el fin de evitar, según una arraigada superstición indígena, que el cadáver denuncie el hecho». Finalmente el cadáver es sepultado en «una zanja de espinas, para que no se desprendieran de su sepultura (7).

Este hecho si bien no es extraordinario para un antropólogo, la anécdota de Camacho sirve para insertar este suceso un marco de significación que enfatiza el salvajismo y el estado de barbarie de los campesinos indígenas.

Esto no sólo justifica a las haciendas en manos de "pequeños blancos» como fortalezas del progreso,

5 Aunque en la narrativa peruana se ha concedido a los abigeos una atmosfera romántica. Es el caso de Enrique López Albùjar, Ciro Alegría o José Varallanos. 


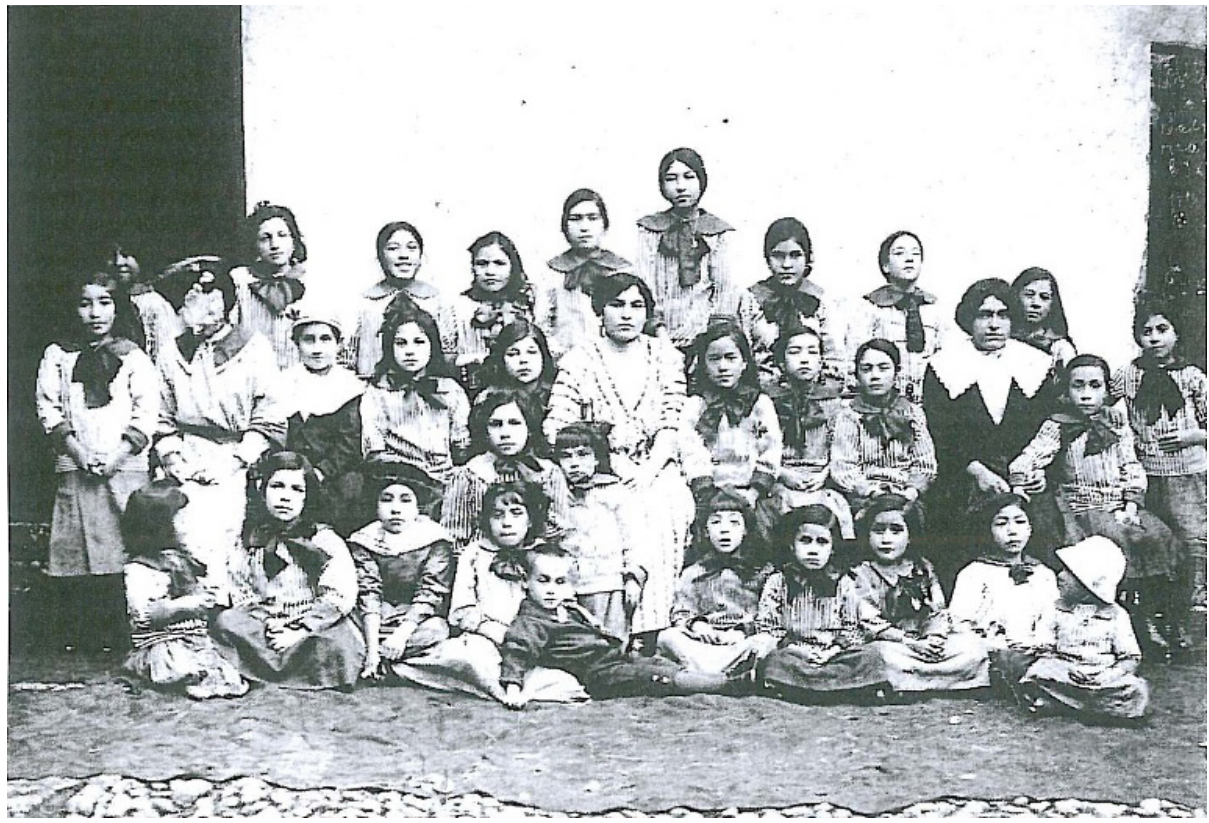

FIGURA 1.

Huancavelica: escuela de niñas mistis, 1920 Fuente. Sala-Guevara (2005:45)

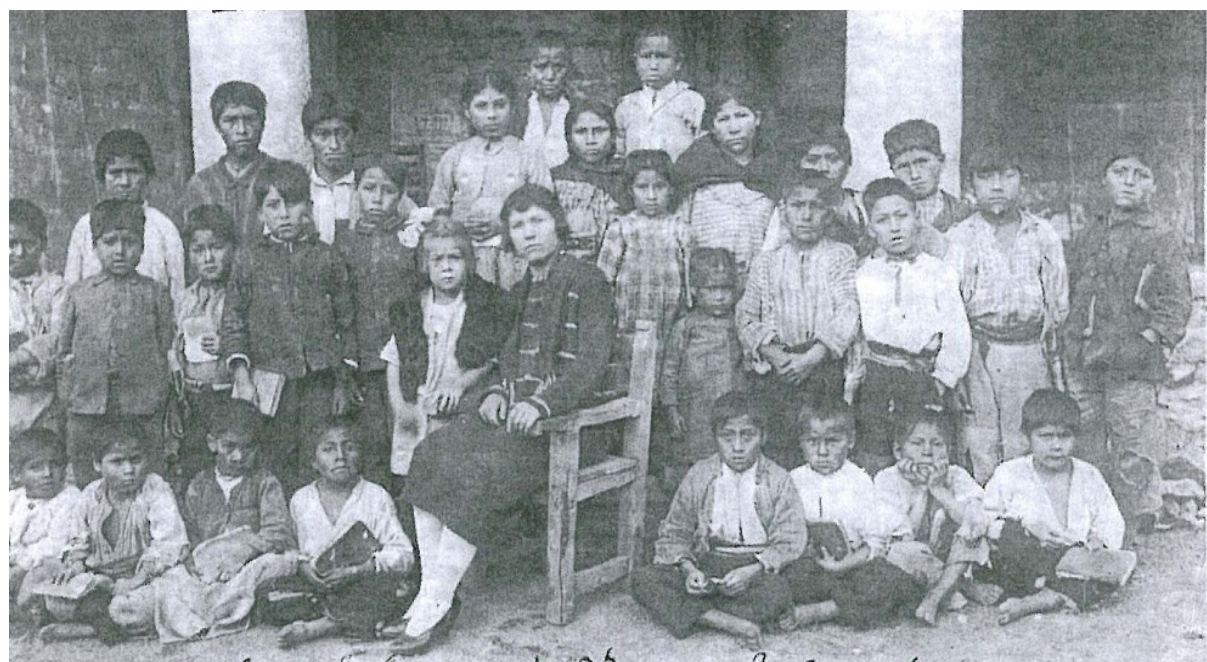

FIGURA 2.

Niños indígenas en una escuela, 1926

Fuente. Academia Nacional de la Historia (2006:813).

sino que justifica acciones de represión y de control social ${ }^{6}$.

Por ejemplo, en los documentos del Archivo Regional de Ayacucho y para nuestra región de estudio, en el período que va de 1920 a 1929, se registraron 116 casos de abigeato, en donde 1921, es el año más representativo, pues son 38 los procesados, casi todos provenientes de pequeños pueblos, como es el

$6 \quad$ La mutilación es una forma de trascender a seres indeseables (vistos como no humanos o sub-humanos) en muchas sociedades, cuando estos parecen poner en peligro la existencia del grupo. Además que la cabeza, las extremidades, la lengua o los genitales, son simbólicamente importantes para el mundo andino. caso de los reincidentes Mariano Ichpas o Melchor Huarancca.

Hasta aquí hemos referido las tensiones y tránsitos obligados y no siempre felices entre hacendados, curas, bandoleros e indios.

\section{Conclusiones}

Los conflictos entre campesinos, hacendados y grupos de poder en la región, estuvieron enmarcados en un constante declive de las clases dirigentes y sus redes de poder. Esta crisis de reproducción terrata- 
niente llega a su cenit con la aplicación de la reforma agraria en el departamento de Huancavelica.

Si en el período colonial se produce una fragmentación de los grupos socio-étnicos, por el mismo tiempo se asiste a un proceso de aculturación generalizada, donde se va perdiendo la identidad primordial para dar nacimiento a la categoría legal de indio. A partir de ahí, la interacción inter-étnica será sólo entendible en el conflicto y la competencia por los recursos sociales y económicos de la región.

Así, se fue forjando un sentimiento de «indianidad» limitada al pueblo o la comunidad, generalmente la comarca de origen toledano (siglo xvI), iniciándose un proceso dialéctico de continuidades y de cambios. Es lo que Wachtel ha llamado el nacimiento de una identidad "a partir de la coyuntura».

Luego, las dificultades del desarrollo capitalista en la región, permitirá que los indicadores socio-étnicos como mecanismos de diferenciación sean importantes. Así mismo, lo que hemos llamado el antiguo régimen (es decir esa estructura social tradicional que fascina los antropólogos) les fue confiriendo a los campesinos comuneros un mundo propio en que la antigua hacienda o los pueblos mestizos (Lircay, Julcamarca, Acobamba) se tornaban en el reverso de la imagen que se habían creado de sí mismos.

Los patronímicos españoles, las fiestas señoriales, el control del poder político local y su incursión en el mundo letrado, les confirieron a estos «pequeńos blancos» un lugar hegemónico en la estructura regional. Las protestas, rencillas y movimientos de distinto alcance (acicateados por sucesos nacionales como la guerra independentista, el conflicto con Chile, las movilizaciones leguiístas y la propia acción campesina a partir de mediados del siglo $\mathrm{xx}$ ) fueron erosionando lentamente este antiguo régimen, hasta su total colapso.

Asimismo, los temas que expresan la «desviación» o la «anormalidad» en sociedades con solidaridad mecánica, como el abigeato o la sexualidad, de hecho otorgan pistas interesantes y reveladoras - por ser clandestinas y transgresoras - de las luchas sociales y étnicas, desvestidas ya, del discurso mistificador o la manipulación simbólica.

Hoy, estas 81 comunidades insertadas en los 11 distritos de la provincia de Angaraes, representan el $13 \%$ del total de comunidades campesinas del departamento (626) y asisten a una modernización acele- rada, propiciada tanto por la presencia cada vez más importante del Estado, cómo por la circulación de mercancías que llegan velozmente por las nuevas carreteras. Permitiendo que los comuneros decidan su participación en la política regional, que estén atentos a sus derechos como productores y ciudadanos y, cómo en una inversión del realismo mágico construyan hoy, su segunda oportunidad sobre la tierra.

\section{Bibliografía}

Abercrombie, T. (2006). Caminos de la Memoria. Etnografía e Historia en una comunidad andina. La Paz: IFEA/IEB.

Academia Nacional de la Historia (2006). Pueblos, provincias y regiones en la historia del Perú. Lima: ANH.

Aguirre, C. y Ch. Walker (ed.) Bandoleros, abigeos y montoneros. Criminalidad y violencia en el Perú. Siglos XVIII$X X$. Lima: IAA.

[Anónimo] (1965). Descripción sobre la provincia de Angaraes. En: Marco Jiménez de la Espada, Relaciones Geográficas de Indias-Perú. Madrid: BAE.

BAschet, J. (2009). La civilización feudal: Europa del año mil a la colonización de América. México: FCE.

Bonila, H. et al. (1981). La independencia en el Perú. Lima: IEP.

Camacho, Mario (1938). Abigeato o cuatrería en la región de Huancavelica. Lima: Tesis de Bachillerato en Jurisprudencia, UNMSM.

Carrasco, T. (2003). Cronología de Huancavelica. Lima: Buenaventura.

Clastres, P (2001). Investigaciones en antropología politica. Barcelona: Gedisa.

Cotlear, D. (1989). Desarrollo campesino en los Andes: cambio tecnológico y desarrollo social en las comunidades de la sierra del Perú. Lima: IEP.

Favre, H. (1976). Evolución y situación de la hacienda tradicional de la región de Huancavelica. Hacienda, comunidad y campesinado en el Perú. J. Matos (comp.) Lima: IEP.

Gamarra, J. (1993). Estado, modernidad y sociedad regional: Ayacucho 1920-1940. Apuntes (31): 103-114.

GARdet, M. (2008). La historia regresiva según Francois Chevalier. Takwa (13): 101-124.

Izko, J. (1991). Fronteras étnicas en litigio. Los ayllus de Sakaka y Kirkyawi (Bolivia), siglos XVI-Xx. Los Andes en la encrucijada. Indios, comunidades y Estado en el siglo 
XIX. H.Bonilla (comp.) Quito: Libri Mundi/FLACSO: 63-131.

Lavallée, D. y M. Julien (1983). Asto: curacazgo prehispánico en los Andes centrales. Lima: IEP.

Molina, Miguel (1995). Antonio de Ulloa en Huancavelica. Universidad de Granada.

O’Phelan, S. (2001). La independencia del Perú. De los Borbones a Bolivar. Lima: Instituto Riva Agüero.

Ossio, J. (1996). Symmetry and Asymmetry in the Andean society. Jornal of the Steward Anthropological Society (24) 1-2.

Plasencia, R. (1997). Conflictos en la sociedad regional: Angaraes, 1896-1950. Anthropologica (15): 135-150.

Plasencia, R. (2016). Comunidades indígenas de Huancavelica: etncidad, conflicto y autonomía en el Perú central, 1880-1980. Tesis de doctor, Departamento de Antropología Social, Facultad de Geografía e Historia, Universidad de Sevilla.

Platt, T. (1987). Entre ch'axwa y Muxsa. Por una historia del pensamiento político aymara. Tres reflexiones sobre el pensamiento andino. La Paz: Hisbol: 61-132.

PoveA, Isabel (2014). Minería y reformismo borbónico en el Perú. Lima: BCRP/IEP.

Raimondi, A. (1942). Notas de viaje para su obra El Perú. Lima: Torres Aguirre, Vol.3: 276-289.

Renard-Casevitz, F. M., Saignes, T. y A. C. Taylor (1988). Al este de los Andes: relaciones entre laa socieda- des amazónicas y andinas, siglos XV y XVII. Quito: Abya Yala/IFEA.

Riviere, G. (1983). «Dualismo e ideología entre los aymaras de Carangas». Boletín IFEA (12) 3-4: 41-62.

Saignes, T. (1985). Los Andes Orientales: historia de un olvido. Cochabamba: CERES/IFEA.

Salas-Guevara, F. (2008). Historia de Huancavelica. 2 t. Lima: Buenaventura.

Scott J. C. y M. SANChis (1997). «Formas cotidianas de rebelión campesina». Historia Social (28):13-39.

Stern, S. J. (1986). Los pueblos indígenas del Perú y el desafio de la conquista española, Huamanga hasta 1640. Madrid: Alianza Editorial.

Szeminski, J. (1984). La utopía tupamarista. Lima: PUCP.

Urrutia, J., Adriano, A. y H. Joyo (1988). «Las comunidades en la región de Huamanga». El Perú: El problema Agrario en debate. Sepia II. Lima: UNSCH/SEPIA: 427-469.

Valdeon, J.; J. M. Salrach y J. Zabalo (). Feudalismo y consolidación de los pueblos hispánicos (siglos XI-XV). Barcelona: Labor.

Vergara, L. (1974). Montoneras y guerrillas en la etapa de la emancipación del Perú (1820-1825). Lima: Editorial Salesiana.

Wachtel, N. (2001). El regreso de los antepasados. Los indios uros de Bolivia, del siglo XX al XVI. México: FCE/El Colegio de México. 